\title{
Synthesis, Structural and Electrical Properties of K- Intercalated Molybdenum Vanadium Oxide Nano-Crystalline Films Prepared by Sol-Gel Method
}

\author{
F.A. Ibrahim \\ Department of Physics, Faculty of Education, Suez Canal University, \\ El-Arish branch, El-Arish, Egypt. \\ E-mail:fahmed_ibrahim@yahoo.com
}

\begin{abstract}
A sol-gel method (colloidal route) based on $\mathrm{V}_{2} \mathrm{O}_{5} \cdot n \mathrm{H}_{2} \mathrm{O}$ hydro-gel was developed to synthesize $x \mathrm{~K}_{2} \mathrm{O}-(80-x) \mathrm{V}_{2} \mathrm{O}_{5}-20 \mathrm{MoO}_{3} \cdot n \mathrm{H}_{2} \mathrm{O}(0 \leq x \leq 20 \mathrm{~mol} . \%)$ material. X-ray diffraction (XRD), Transimition electron microscopy (TEM), density, thermoelectric power, and Electrical properties of the as prepared films were investigated. X-ray diffraction, transmission electron micrograph and electron diffraction were used to identify the structure of the obtained nanocrystals. Homogenous nanocrystals of $10.2 \mathrm{~nm}$ in size were obtained and were closed packed and are distributed evenly. The density of the samples decreases with increasing $K$-content. Electrical conductivity and thermoelectric power were measured in the temperature range 300-500 K for the as prepared films. The electrical conductivity showed that all samples were semiconductors and that conductivity increased with increasing $K$ content. The carrier density was evaluated as well. The obtained results showed by increasing $K$ content in the system under investigation, gradual changes in thermoelectric power from $n$ - type to $p$ - type detected. The sol-gel method is fit for the preparation of $x \mathrm{~K}_{2} \mathrm{O}-(80-x) \mathrm{V}_{2} \mathrm{O}_{5}-2 \mathrm{MoO}_{3} . \mathrm{nH}_{2} \mathrm{O}$ material which may offer some favorable properties for commercial application.
\end{abstract}

\section{Introduction}

Vanadium oxides represent an important family of transition metal compounds that have received considerable attention from both the scientific and technological communities. These oxides present fascinating electronic, optical, magnetic, electrochemical and structural properties, which make them suitable for several applications in catalysis, cathodes for $\mathrm{Li}^{+}$batteries, electrochromic devices, thermochromic windows, sensors, solar cells and field effect transistors (FETs), among others (1). Mo doped vanadium oxides have found a wide range of applications because of their selective oxidation as well 
as the unique interaction between $\mathrm{V}_{2} \mathrm{O}_{5}$ and $\mathrm{MoO}_{3}$ owing to the similarity of ionic radii and the structures in their highest oxidation state (2). Sol-gel methods, with different synthesis routes and different precursor-products, can result in markedly different structures and morphologies of materials, and have been widely used in synthesis of nanosized materials.

During the last two decades, many gel products of vanadium pentoxides have been prepared by sol-gel methods, such as hydrogels, xerogels, aerogels, bronzes and other oxides (3). Considerable progress was achieved over the last years in synthesizing divanadium pentoxide nanotubes (NTs) by various growth methods. These NTs have attracted much attention due to their interesting applications in catalysis and as nanoscale materials for lithium microbatteries. It is obvious that successful technological application of metal oxide NTs depends on the stability of properties of the synthesized materials and the possibility to vary these properties (4).

Vanadium pentoxide-based xerogels, $\mathrm{H}_{2} \mathrm{~V}_{12} \mathrm{O}_{31} \cdot \mathrm{y} \cdot \mathrm{nH}_{2} \mathrm{O}$, have been extensively studied over past years because of their particular properties. These materials can be used as reversible cathodes in lithium batteries, electrochromic layers for display devices, host materials for the intercalation of guest species, humidity sensors, starting material for switching elements, etc. (Bach et al., 1990; Livage, 1996; Aldebert et al., 1981; Bondarenka et al., 1995). These xerogels have a layered structure, where $\mathrm{V}_{2} \mathrm{O}_{5}$ chains are bonded by interlayer water, and can intercalate guest ions and molecules (5). The partial substitution of vanadium ions by molybdenum or chromium in $\mathrm{H}_{2} \mathrm{~V}_{12} \cdot \mathrm{xMxO}_{31} \cdot \mathrm{y} \cdot \mathrm{nH} 2 \mathrm{O}$, leads to the strong decrease in electronic conductivity and the exponential dependence of the total conductivity on relative humidity (Aldebert et al., 1981; Bondarenka et al., 2004). Various deposition techniques such as epitaxial growth by melting, chemical vapor deposition, liquid phase epitaxy, sputtering and sol gel have been used for this compound [6-12]. If cost effective is of prime concern, sol-gel method is the preferred thin film fabrication technique for many applications. Optical, electrical and thermoelectric power properties of $\mathrm{Li}$ - ions intercalated vanadium pentoxide, $\mathrm{Li}_{\mathrm{x}} \mathrm{V}_{2} \mathrm{O}_{5} \cdot \mathrm{nH}_{2} \mathrm{O}$, films were studied recently[16;17]. It was shown recently that the xerogel specimens prepared by the $\mathrm{V}_{2} \mathrm{O}_{5}$ melt-water quenching technique revealed that the conduction mechanism is due to non-adiabatic small polaron hopping[17]. On the other hand, a more recent study of the structure properties of $\mathrm{K}_{\mathrm{x}} \mathrm{V}_{2} \mathrm{O}_{5} \cdot \mathrm{nH}_{2} \mathrm{O}$ xerogels shows nanocrystalline layer structure of rod like particles[18]. Volkov et al.[19] on the other hand have demonstrated that the electrical conductivity of pressed $\mathrm{M}_{2} \mathrm{~V}_{12} \mathrm{O}_{30} \cdot \mathrm{nH}_{2} \mathrm{O}(\mathrm{M}=\mathrm{K}, \mathrm{Rb}, \mathrm{Cs})$ samples is mainly due to charge transport across the $\mathrm{V}-\mathrm{O}$ layers. In this paper, the electrical properties of films prepared by sol-gel method (colloidal route) and deposited by a dip-coating process are 
presented. Second aim of this work is investigate the structure and the compositional dependence of the electrical conduction mechanism and thermoelectric power properties of $\mathrm{xK}_{2} \mathrm{O}-(80-\mathrm{x}) \mathrm{V}_{2} \mathrm{O}_{5}-20 \mathrm{MoO}_{3} \cdot \mathrm{nH}_{2} \mathrm{O}$ xerogel.

\section{Experimental techniques}

$\mathrm{V}_{2} \mathrm{O}_{5} \cdot \mathrm{nH}_{2} \mathrm{O}$ xerogel was firstly prepared by sol-gel technique (colloidal route) as follows; hydrogen peroxide $\mathrm{H}_{2} \mathrm{O}_{2}$ solution was slowly added to $\mathrm{V}_{2} \mathrm{O}_{5}$ and stirred at $60 \mathrm{C}$ temperature until a clear orange solution formed, then turned into a red solution after $2 \mathrm{~h}$ and then turned into a brownish homogeneous solution after $2 \mathrm{~h}$. Molybdenum oxide $\left(\mathrm{MoO}_{3}\right)$ was secondly prepared by the same way until yellow solution formed. The resulting mixture was stirred for about $2 \mathrm{~h}$ and the stirring continued for $6 \mathrm{~h}$ and hydrolyzed vanadium pentoxide and molybdenum oxide component was obtained[11]. Then, distilled water was added to $\mathrm{K}_{2} \mathrm{Co}_{3}$ and the stirring continued until became pure solution. The resulting solution was added with different amounts to the above resulting mixture and strongly stirred at $60 \mathrm{C}$ temperature. Red brown viscous gels, or colloidal solutions are formed within few days by heating the solution at $60 \mathrm{C}$. Dip coating method was used to form the film on clean $1.5 \mathrm{~mm}$ thick high quality Pyrex glass substrates. The density of $\mathrm{xK}_{2} \mathrm{O}-(80-\mathrm{x}) \mathrm{V}_{2} \mathrm{O}_{5}-20 \mathrm{MoO}_{3} \cdot \mathrm{nH}_{2} \mathrm{O}$ samples, which was left to dry independently under ambient conditions for one month, has been determined experimentally by Archimedes method using toluene as the immersion liquid [12]. On the other hand the films were made in a coplanar geometry and dried spontaneously in ambient conditions to orient the layered plane. The surface morphology of the films was observed using a transmission electron microscope, TEM, (Jeol, Jem-1010) to investigate the crystal structure of particles in which an TEM observation was performed at an accelerating voltage of $70 \mathrm{kV}$, while it was just $40 \mathrm{kV}$ in case of electron diffraction, ED. The structure was determined by applying $\mathrm{X}$-ray diffraction (XRD), using Philips P.W.1390 diffractometer with a $\mathrm{Cu} \mathrm{K} \alpha$ target and $\mathrm{Ni}$ filter.

Dc electrical conductivity was performed on the films using the twoprobe technique, in coplanar geometry parallel to the substrate surface. A thermoelectric power (TEP) measurement above room temperature. Temperature dependent electrical conductivity, $\sigma(\mathrm{T})$, and thermoelectric power, $\mathrm{S}$, were measured independently in the temperature range from 25 up to $180^{\circ} \mathrm{C}$ in air. The general expression for $\mathrm{S}$ in the case of nanocrystalline semiconductors is $\Delta \mathrm{V} / \Delta \mathrm{T}$ where $\Delta \mathrm{V}$ is the voltage developed between two points of the material is maintained at temperature $\Delta \mathrm{T}$ [13]. The thermoelectric power is defined by [13]. 


\section{Results and Discussion}

\subsection{Structure}

XRD patterns of the present films are shown in Fig. 1. From this figure the XRD peaks which are observed and identified are (001), (002), (003), (004), and (005) indicate a preferred orientation. These results are in good agreement with the JCPDS card: 40-1296, where the lattice constants for pure $\mathrm{V}_{2} \mathrm{O}_{5} \cdot \mathrm{nH}_{2} \mathrm{O}$ was evaluated using Rietveld refinement program, crystal structure: Orthorhombic system, Space group: $($ Pmmn), Lattice parameters: $\mathrm{a}=1.1998$ $\mathrm{nm}, \mathrm{b}=0.3778 \mathrm{~nm}, \mathrm{c}=1.24 \mathrm{~nm}, \alpha=\beta=\gamma=90^{\circ}$. The XRD patterns of the films show the stacking of the vanadium pentoxide xerogel ribbons parallel to the glass substrate surface while vanadium oxygen layers are formed by tangled fibers and connected by water molecules [11]. However, Fig. 1 shows that all patterns reveal the same general features suggesting that the structure of the films were unaltered by the intercalation of the foreign alkaline $\mathrm{K}^{1+}$ cations. The average particle sizes, $\mathrm{D}$, of the precipitated nanocrystals were calculated according to Sherrer's formula [14];

$$
\mathrm{D}=\mathrm{k} \lambda / \beta \cos \theta
$$

$\mathrm{D}$ was found to be on the average $10.2 \mathrm{~nm}$. Where $\mathrm{k} \sim 1, \lambda(\mathrm{nm})$ represents the wavelength of $\mathrm{Cu} \mathrm{K} \alpha$ radiation; $\theta$ is the Bragg angle of the X-ray diffraction peak and $\beta$ represents the corrected full width at half maximum of the diffraction peak in radians.

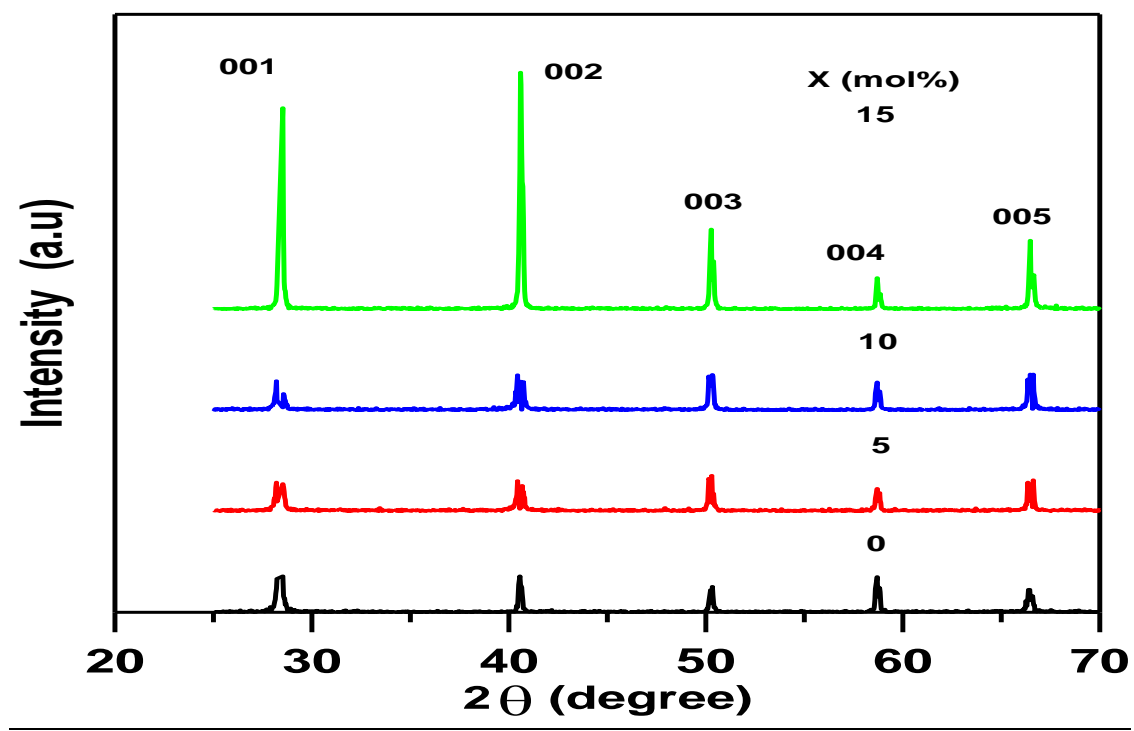

Fig. (1): $\mathrm{XRD}$ of $\mathrm{xK}_{2} \mathrm{O}-(80-\mathrm{x}) \mathrm{V}_{2} \mathrm{O}_{5}-20 \mathrm{MoO}_{3} \cdot \mathrm{nH}_{2} \mathrm{O}$ films grown on Pyrex glass substrate and measurements at room temperature 
Morphology of the film surface on the other hand was evaluated using TEM. It was found that the film surface was relatively smooth with an average size of $10 \mathrm{~nm}$ in close agreement with $\mathrm{X}$-ray results shown above. Fig.(2 a,b) on the other hand shows that $\mathrm{xK}_{2} \mathrm{O}-(80-\mathrm{x}) \mathrm{V}_{2} \mathrm{O}_{5}-20 \mathrm{MoO}_{3} \cdot \mathrm{nH}_{2} \mathrm{O}$ samples $(\mathrm{x}=5,20$ respectively) have a uniform layer stacking and indicating that films under test are close packed and interacting with each other through weak force. While Fig. $2 \mathrm{c}$ shows the electron diffraction, $\mathrm{ED}$, pattern for $20 \mathrm{~K}_{2} \mathrm{O} 20 \mathrm{~K}_{2} \mathrm{O}-60 \mathrm{~V}_{2} \mathrm{O}_{5}-20 \mathrm{Mo}$ which indicates grains as indicated by the ordered diffraction spots in confirmation to the X-ray diffraction results. The samples was pulled off the substrate by mechanical means. The ED micrograph shows diffraction spots.

(a)

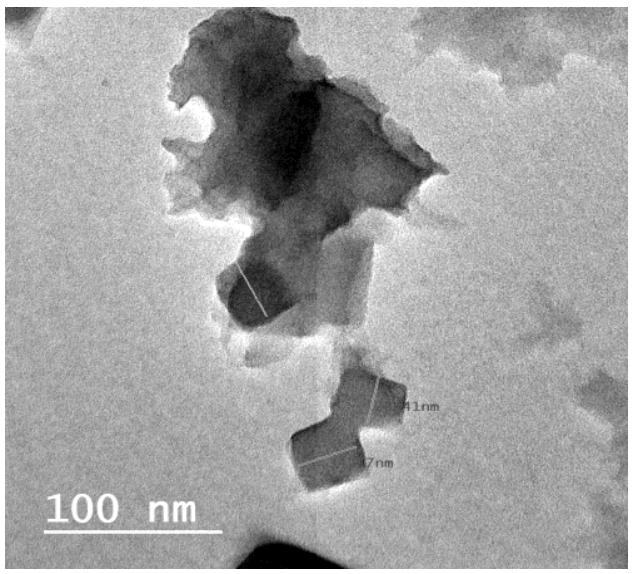

(b)

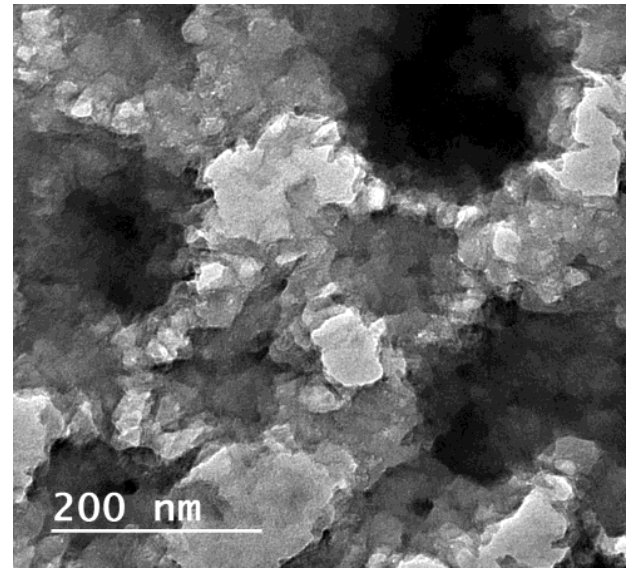

(c)

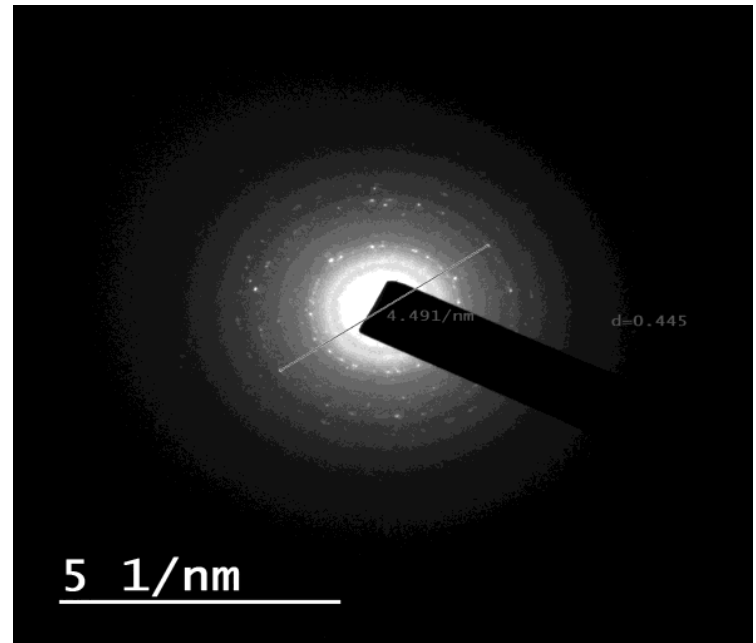

Fig. (2. a, b): TEM and c) ED of the $\mathrm{xK}_{2} \mathrm{O}-(80-\mathrm{x}) \mathrm{V}_{2} \mathrm{O}_{5}-20 \mathrm{MoO}_{3} \cdot \mathrm{nH}_{2} \mathrm{O}$ films (for TEM, $\mathrm{x}=5,20$ and $\mathrm{ED}, \mathrm{x}=20$ ) 


\subsection{Density}

The density of $\mathrm{xK}_{2} \mathrm{O}-(80-\mathrm{x}) \mathrm{V}_{2} \mathrm{O}_{5}-20 \mathrm{MoO}_{3} \cdot \mathrm{nH}_{2} \mathrm{O}$ system $(0 \% \leq \mathrm{x} \leq 20 \%)$ has been calculated. Figure (3) shows the composition dependence of density (d) of the present system. It may be observed that the density (d) decreases gradually with increasing potassium content. In the current system, the density varies from 3.71 to $1.56 \mathrm{~g} / \mathrm{cm} 3$. The decrease in the density with increasing potassium content may also be due to the raise of intercalated water molecules, of less molecular weight, $\mathrm{K}$ ions of higher molecular weight on the average. The density of the present system is consistent with the ionic size, atomic weight and amount of element $\mathrm{K}^{+}$. In comparison with the $\mathrm{V}_{2} \mathrm{O}_{5} \cdot \mathrm{nH}_{2} \mathrm{O}$ xero-gel sample prepared by the melt-water procedure[17], the density was found to be $1.26 \mathrm{~g} / \mathrm{cm} 3$ which is in support to the single layer model[24,25]. The amount per unit volume of vanadium ions $\mathrm{N}\left(\mathrm{cm}^{-3}\right)$ may be evaluated using the density by the relation:

$$
N=\frac{d p N_{A}}{A_{W}}
$$

where $d$ is the density of the sample as evaluated and presented in Table (1), p is the weight percentage of atoms, $\mathrm{N}_{\mathrm{A}}$ is the Avogadro's number and $\mathrm{A}_{\mathrm{W}}$ is the molecular weight.

While the relationship between $\mathrm{N}$ and the mean inter-atomic distance $\mathrm{R}$ is generally described as:

$$
R=(1 / N)^{1 / 3}
$$

The calculated values of $\mathrm{R}$ and $\mathrm{N}$ are summarized in Table (1).

Table (1): Physical parameters of the films under test

\begin{tabular}{l|l|l|l|l|l|l|l}
\hline $\begin{array}{c}\text { Compositio } \\
\mathrm{n} \times(\mathrm{mol} \%)\end{array}$ & $\mathrm{d}\left(\mathrm{g} \mathrm{cm}^{-3}\right)$ & $\begin{array}{c}(W) \Delta E_{\sigma}, \\
(\mathrm{eV})\end{array}$ & $\begin{array}{c}\mathrm{N}\left(\times 10^{22}\right. \\
\left.\mathrm{cm}^{-3}\right)\end{array}$ & $\mathrm{R}(\mathrm{nm})$ & $\theta_{\mathrm{D}}(\mathrm{K})$ & $\mathrm{S}(\mu \mathrm{V} / \mathrm{K})$ & $\ln \sigma_{0}\left(\Omega . \mathrm{m}^{)-1}\right.$ \\
\hline 5 & 3.5789 & 0.241 & 6.2612 & 0.5426 & 385 & 0.9 & -2.8 \\
10 & 3.4642 & 0.223 & 12.2769 & 0.4335 & 383 & 13 & -6.5 \\
15 & 1.7058 & 0.201 & 9.1859 & 0.4775 & 386 & -0.2 & -1.2 \\
20 & 1.5636 & 0.194 & 11.3749 & 0.4446 & 385 & 0.3 & -3.5 \\
\hline
\end{tabular}




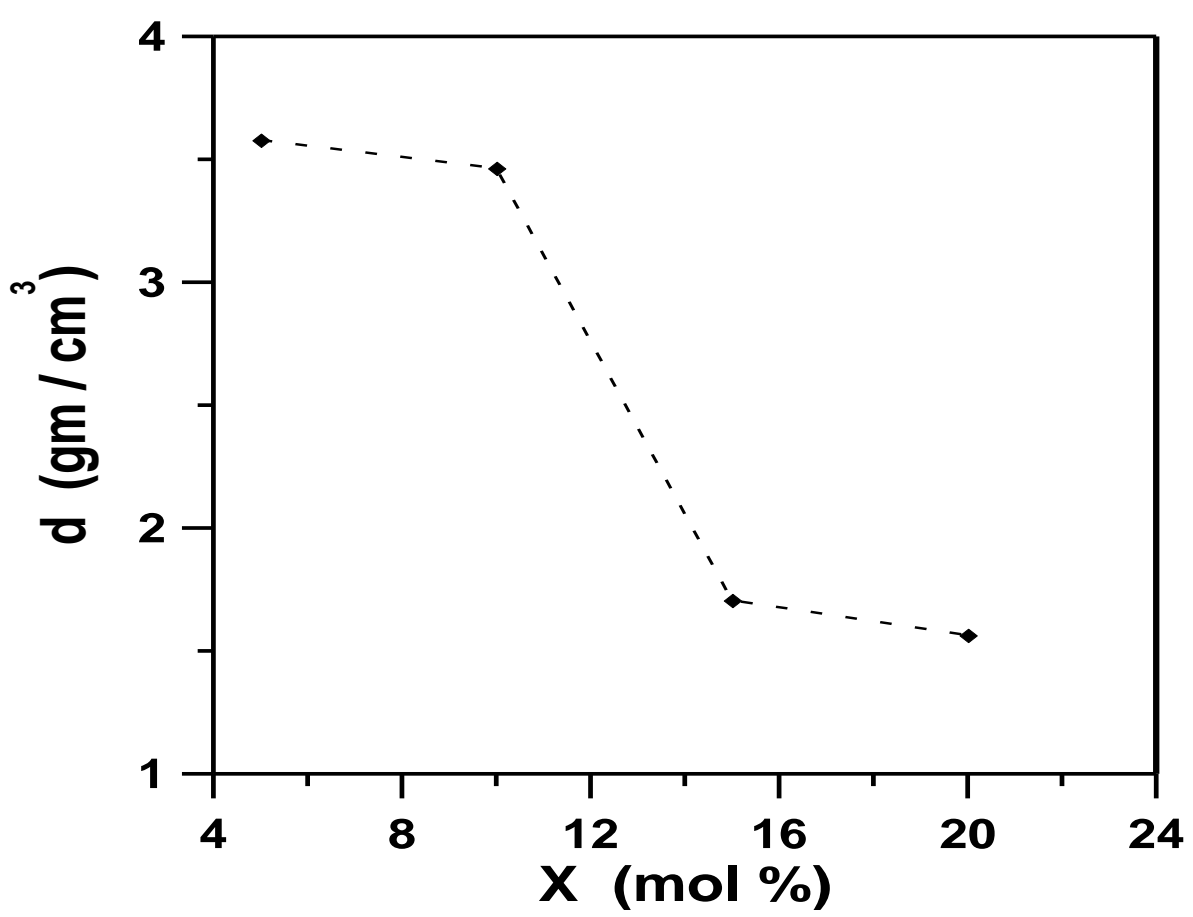

Fig.(3): Compositional density dependence on $\mathrm{K}$ ions content of the films under test

\subsection{Electrical properties}

The electrical properties of the films under investigation were investigated as a function of the degree of intercalation (Fig. 4) and the temperature in the range $300-500 \mathrm{~K}$. The obtained variation of d.c conductivity as a function of temperature $(1 / \mathrm{T})$ for the investigated compositions is illustrated in Fig.(4). The plots suggest that there is a conduction mechanism, which contributes to conductivity in the considered range of temperature.

Fig. (4), shows the d.c conductivity $\sigma_{\mathrm{dc}}$ exhibits activated temperature dependence, in accordance with the relation [21]:

$$
\sigma=\sigma_{o} \exp \left(-\Delta E_{\sigma} / k T\right)
$$

where $\sigma_{o}$ is the pre-exponential factor and includes the charge carrier mobility and density of states, $k$ is the Boltzmann's constant, $T$ is the absolute temperature and $\Delta E_{\sigma}$ is the conduction activation energy which is a function of the energy band gap. 
The electrical properties of the samples were investigated as a function of the degree of intercalation as shown in Fig. (4) in the temperature range of $300-500 \mathrm{~K}$. The activation energy, $\Delta E_{\sigma}$, and pre-exponential factor, $\sigma_{o}$, were obtained from the least square straight line fits of the data. The relatively small values of , $\sigma_{o}$ obtained in the present work in comparison to the almost universal predicted value $\left(10^{4}\right.$ to $\left.10^{5} \mathrm{~S} . \mathrm{m}^{-1}\right)$ [21] may be an indication of a wide range of localized states as well as conduction by hopping. Additional explanation may be due to that if long-range fluctuations in potential exist, tunneling through the maximum is possible and, $\sigma_{o}$ would be smaller. The dc conductivity indicates that the activation energy, $\Delta E_{\sigma}$, decreases $(0.241-0.194 \mathrm{eV})$ as in Fig (5) while the magnitude of the conductivity increases with increasing $\mathrm{K}$ content, this may be due to the small ionic size of the potassium ion when compared with that of $\mathrm{H}_{2} \mathrm{O}$ group. The activation energy $\Delta E_{\sigma}$, (W) is temperature dependent. However, above this temperature range, the variation of activation energy with temperature is negligibly small so that the behavior may be treated as thermally activated process.

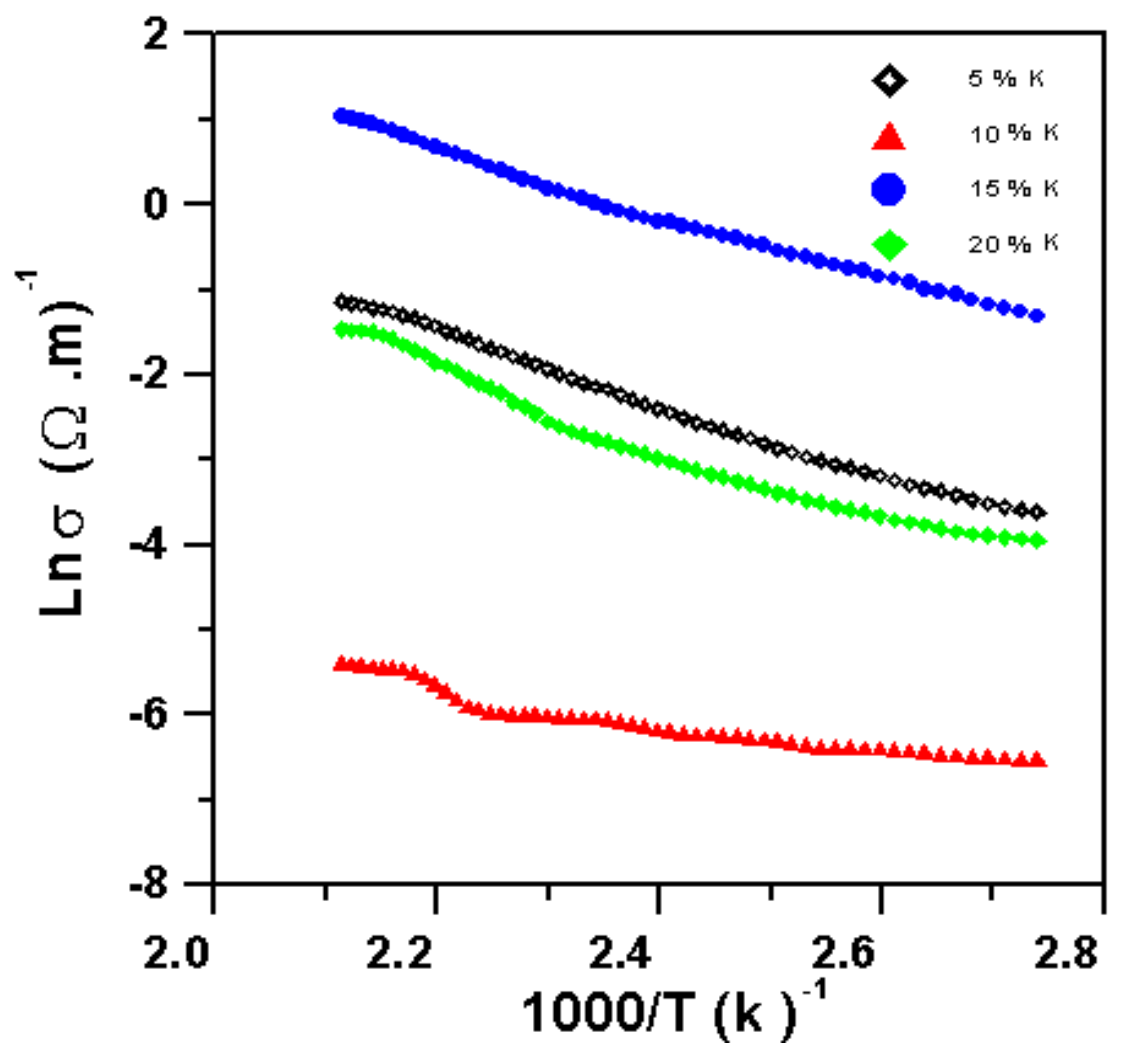

Fig. (4): Temperature dependence of d.c electrical conductivity for the investigated films for heating at room temperature 


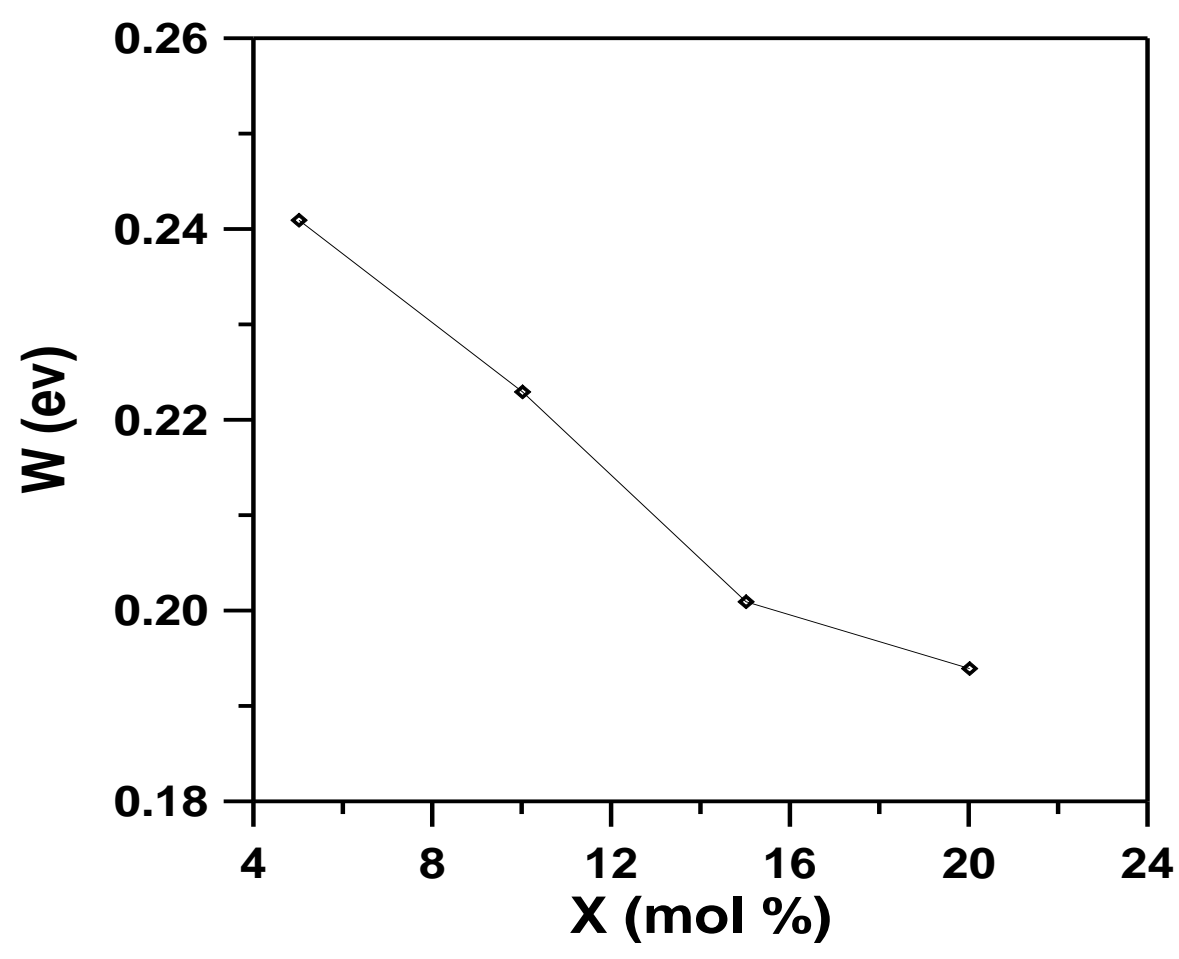

Fig. (5): Effect of K-content on activation energy $\Delta E_{\sigma},(\mathrm{W})$ for the investigated films.

The compositional dependence of the conductivity $(\sigma)$ at $400 \mathrm{~K}$ and the activation energy $\Delta E_{\sigma}$, (W) are shown in Fig (5) and in Table (1). A general trend observed in this table is that the magnitude of the conductivity at fixed temperature tends to be highest in those compositions and having low value for activation energy (Fig,5).

\subsection{Thermoelectric power}

Thermoelectric power of $\mathrm{xK}_{2} \mathrm{O}-(80-\mathrm{x}) \mathrm{V}_{2} \mathrm{O}_{5}-20 \mathrm{MoO}_{3} \cdot \mathrm{nH}_{2} \mathrm{O}$ films has been investigated as a function of temperature above room temperature. Figure (6) shows the temperature dependence of thermoelectric power of the films without heat-treated. At temperatures $(\mathrm{T}<341 \mathrm{~K})$ thermoelectric power has small negative values and is practically independent of temperature which indicates metallic properties.

The general expression for $S$ in case of amorphous semiconductors, in case where carriers are excited to appropriate extended states beyond the mobility edges, is given by [21]: 


$$
S= \pm(k / e)\left[\left(\Delta E_{s} / k T\right)+A\right]
$$

where $A$ is a small constant and represents the thermal energy transported by carriers, $e$ is the electronic charge and $\Delta E_{s}$ is the activation energy associated with conduction.

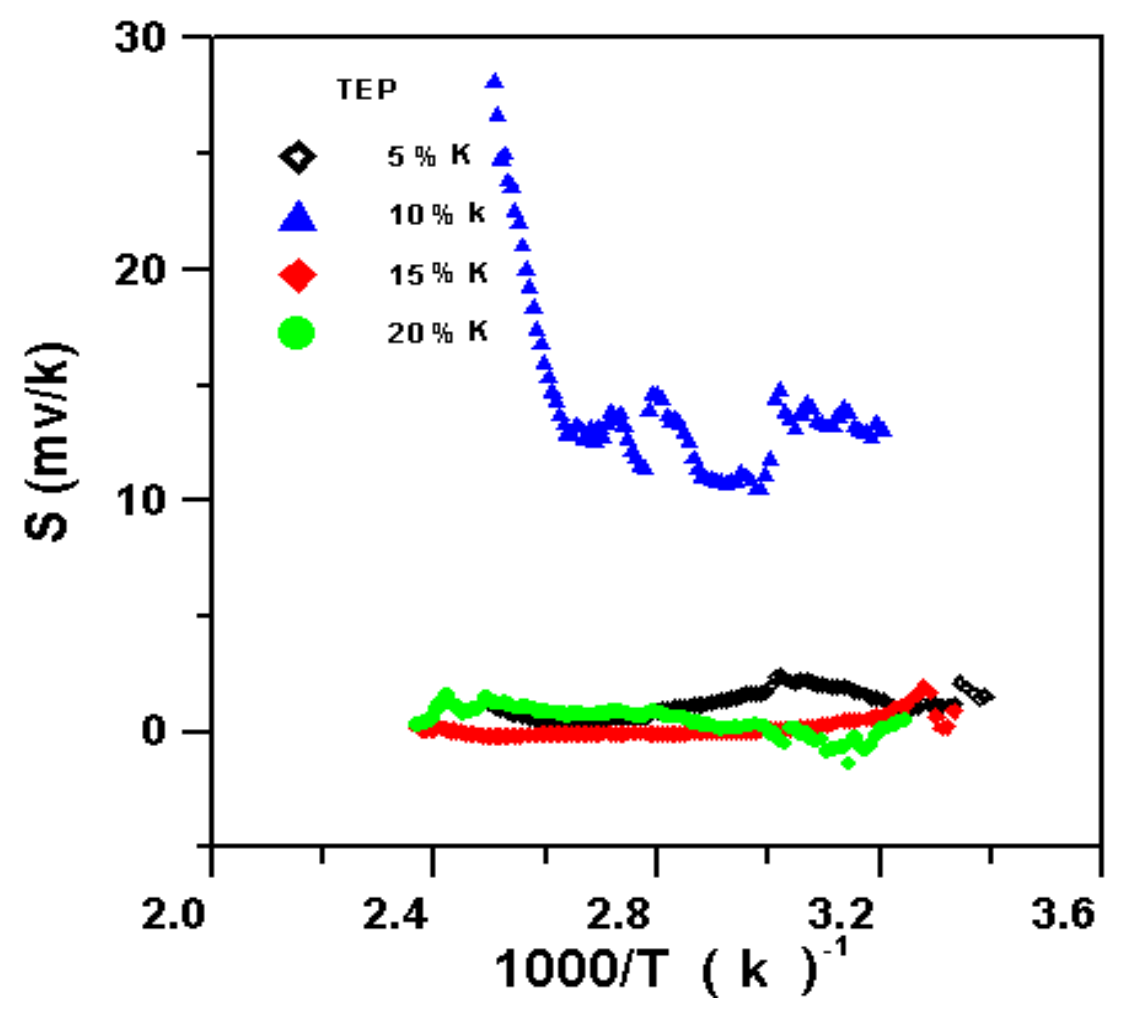

Fig. (6): Thermoelectric power for the investigated films as cast in air as a function of temperature

Figure (6) shows the different thermoelectric power, TEP, measurements corresponding to the as the different content of $\mathrm{K}$. The temperature dependence of thermoelectric power $S$ measures the energy difference between the Fermi energy and the energy level where charge transport occurs. It is found that $\Delta E_{s}=0.186-0.231 \mathrm{eV}$ in agreement with the activation energy, $\Delta E_{\sigma}$, (W), obtained from the electrical conductivity. It is found that the activation energy $\Delta E_{s}$ calculated from the slope of $S$ vs. $1 / T$ curve (Fig.6) is consistent with the obtained results of electrical conductivity measurements. On increasing $\mathrm{K}$ content in the system $x \mathrm{~K}_{2} \mathrm{O}-(80-\mathrm{x}) \mathrm{V}_{2} \mathrm{O}_{5}-20 \mathrm{MoO}_{3} \cdot \mathrm{nH}_{2} \mathrm{O}$, gradual changes in 
thermoelectric power from $n$ - type to p- type detected as shown in Figs. ( $6 \&$ 7) and as presented previously[23]. This is a planned advantage aiming for different practical applications.

The temperature dependence of thermoelectric power $S$ measures the energy difference between the Fermi energy and the energy level where charge transport occurs. It is interesting to note that $\Delta E_{s}$ is slightly smaller than $\Delta E_{\sigma}$. The difference between $\Delta E_{s}$ and $\Delta E_{\sigma}$ can be attributed to a mobility activation energy.

The optical temperature coefficient can be calculated from the thermoelectric power through the Peltier coefficient ( $)$. The Peltier coefficient is calculated according to the following equation [21]:

$$
\Pi=-(k / e)\left[\left(\Delta E_{s} / k\right)-(\gamma T / k)+A T\right]
$$

where $\Pi$ is plotted as a function of temperature for films under investigation. Figure (7) show Peltier coefficient (П) against temperature, which have a slope equal to $-(\gamma / e-k / e)$, where $\gamma$ is the optical temperature coefficient. The obtained values of $\gamma$ were found to have a magnitude of $10^{-3} \mathrm{eV} / \mathrm{K}$.

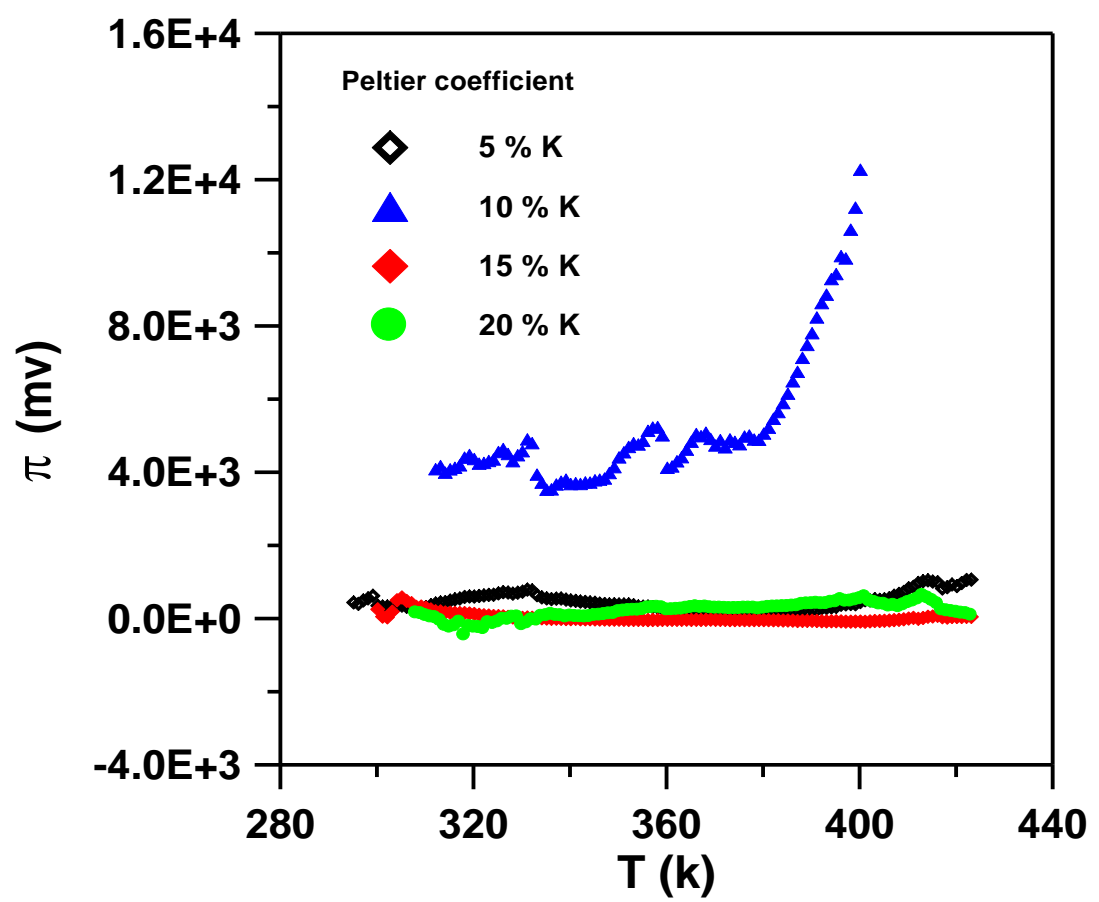

Fig. (7): Peltier coefficient, (П), as a function of temperature for the investigated films 


\section{Conclusion}

The aim of this study was to determine an effect of potassium excess in nanocrystalline $\mathrm{xK}_{2} \mathrm{O}-(80-\mathrm{x}) \mathrm{V}_{2} \mathrm{O}_{5}-20 \mathrm{MoO}_{3} \cdot \mathrm{nH}_{2} \mathrm{O}$ thin films $(0 \leq \mathrm{x} \leq 20 \mathrm{~mol} \%)$ on their electrical and structural properties. Samples under investigation have been successfully prepared by the sol-gel process. The density of the samples decreases with increasing potassium content. The dc electrical conductivity and thermo-electric power measurements show that: The electrical conductivity indicates that all samples are semi-conductors and increases with increasing potassium content. The activation energy decreases with increasing $\mathrm{K}^{+1}$ ions content. The samples are changes in thermoelectric power from $\mathrm{n}$ - type to $\mathrm{p}$ - type semiconductors.

\section{Refrence}

1. Willian G. Menezes, Dayane M. Reis, Tânia M. Benedetti, Marcela M. Oliveira, Jassa F. Soares, Roberto M. Torresi b, Aldo J.G. Zarbin, Journal of Colloid and Interface Science, 337, 586 (2009).

2. Li-Qiang Mai, Wen Chen, Qing Xu, Jun-Feng Peng, Quan-Yao Zhu Chemical Physics Letters, 382, 307 (2003).

3. Lisheng Gaoa, Xiong Wanga, Linfeng Feib, Mingrong Jib, Huagui Zhenga, Hanchang Zhanga, Tao Shenc, Kai Yang. Journal of Crystal Growth, 281, 463 (2005).

4. A.N. Enyashin, V.V. Ivanovskaya, Yu.N. Makurin, V.L. Volkov, A.L. Ivanovskii. Chemical Physics Letters, 392, 555 (2004).

5. S. Mickevic 'ius, V. Bondarenka, S. Grebinskij, H. Tvardauskas, M. Andriulevic`ius, S. Tamulevic `ius, S. Kac`iulis. Micron, 40, 126 (2009).

6. S. Miyazama, Appl. Phys. Lett. 23 (1973) 198.

7. B.J. Curtis, H.R. Brunner, Mater. Res. Bull., 10, 515 (1975).

A. Rasch, M. Rootschalk, W. Karthe, J. Opt. Commun., 3, 14 (1985).

8. T.A. Rabson, R.C. Baumann, T.A. Rost, Ferroelectrics, 112, 265 (1990).

9. S. Hirano, K. Kato, Adv. Ceram. Mater., 3, 503 (1988).

10. A.A. Bahgat, F.A. Ibrahim and M.M. El-Desoky, Thin Solid Films, 489, 68 (2005).

11. M.S. Al-Assiri, M.M. El-Desoky, A. Alyamani, A. Al-Hajry, A. Al Mogeeth, A.A.Bahgat, Opt. Laser Technol. 42, 994 (2010).

12. R.R. Heikes, R.W. Ure (Eds.), Thermoelectricity, Inter Science, New York, (1961).

13. D. Lou, N. Audebrand, Adv. X-ray Anal., 41, 556 (1997).

14. J. Livage: Chem. Mater., 3, 578 (1999). 
15. M.S. Al-Assiri, M.M. El-Desoky, A. Alyamani, A. Al-Hajry, A. Al-Mogeeth and A.A. Bahgat, Opt. Laser Technol., 42, 994 (2010).

16. M.S. Al-Assiri, M.M. El-Desoky, A. Alyamani, A. Al-Hajry, A. Al-Mogeeth and A.A. Bahgat: Philos. Mag., 90 (25), 3421 (2010).

17. S.E. Negm, H.A. Mady, A.S. Abd-Moghny, A.S. Abd-Rabo and A.A. Bahgat: Solid State Sci., 13, 590 (2011).

18. V.L. Volkov and N.V. Podval'naya, Inorg. Mater., 40 (11), 1217 (2004).

19. G.T. Chandrappa, N. Steunou, S. Cassaignon, C. Bau-vais and J. Livage, Catal. Today, 78, 85 (2003).

20. N.F. Mott and E.A. Davis, "Electronic Process in Noncrystalline Materials", (Clarendon Press, Oxford, (1971).

21. A.A. Bahgat and Y.M. Abou-Zeid, J. Phys. Chem. Glasses, 42 (6), 361 (2001)

22. Y.J. Liu, J.A. Cowen, T.A. Kplan, D.C. De Groot, J. Schindler, C.R. Kannewurf and M.G. Kanatzidis, Chem. Mater., 7, 1616 (1995).

23. J. Livage, Coord. Chem. Rev., 190, 391 (1999).

24. P. Aldebert, N. Baher, N. Gharbi and J. Livage: Mater. Res. Bull., 25, 16 (1981). 